Eur. J. Clin. Chem. Clin. Biochem.

Vol. 32, 1994, pp. $669-673$

(c) 1994 Walter de Gruyter \& Co.

Berlin - New York

\title{
Lysosomes and Human Liver Disease: \\ A Biochemical and Immunohistochemical Study of $\beta$-Hexosaminidase
}

By M. E. Elsafi ${ }^{1}$, B. Hultberg ${ }^{2}$, A. Isaksson ${ }^{2}$, Inga Hägerstrand ${ }^{1}, H_{\text {. Prytz }}{ }^{3}$ and U. Stenram ${ }^{1}$

1 Department of Clinical Pathology

2 Department of Clinical Chemistry

${ }^{3}$ Department of Internal Medicine

University Hospital, Lund, Sweden

(Received March 7/June 2, 1994)

Summary: Liver biopsies from 88 patients with different liver diseases were studied for $\beta$-hexosaminidase activity. Liver specimens with normal light microscopical morphology showed no immunohistochemical reactivity for $\beta$ hexosaminidase. Increased reactions were noted, mainly in hepatocytes, in biopsies from the patients with different liver diseases. A very large interindividual variation of biochemical liver $\beta$-hexosamindase activity occurred even within the same diagnostic group, and no group of patients showed any significant increase of liver $\beta$-hexosaminidase activity compared with the patients with normal liver histology. Livers with positive immunohistochemistry showed increased biochemical values for $\beta$-hexosaminidase. In patients with cholestasis due to alcohol abuse, the immunohistochemical reaction was intense and the biochemical $\beta$-hexosaminidase activity was significantly increased compared with non-alcoholic cholestatic cases. Furthermore, blood samples were taken from 50 patients at the same time as the liver biopsies. These patients showed significantly increased serum $\beta$-hexosaminidase activity compared with normal controls, but no correlation was found between $\beta$-hexosaminidase activities in the liver and serum of these patients.

\section{Introduction}

Lysosomal storage diseases are diagnosed by absence or low activity of a specific enzyme in plasma and/or in tissue (1). Otherwise, determination of lysosomal enzymes is rarely used for clinical purposes. From earlier studies in humans and rats we know that the lysosomal enzyme, $\beta$-hexosaminidase ${ }^{1}$ ) is increased in serum as well as in liver and spleen tissue in cholestasis and cirrhosis (2-5). In long standing experimental cholestasis, lysosomal enzymes are also increased in lungs, due to a heavy accumulation of macrophages rich in lysosomes in alveoli and in pulmonary veins (4). In a retrospective immunohistochemical study on paraffin-embedded human liver biopsies, we showed an increased content of

\footnotetext{
1) Enzyme

$\beta$-Hexosaminidase $(\beta-\mathrm{N}$-acetyl- $D$-glucosaminide $\mathrm{N}$-acetylglucosaminohydrolase, EC 3.2.1.30)
}

$\beta$-hexosaminidase in hepatocytes and to some extent in Kupffer cells in various types of liver disease (6).

All lysosomal enzymes are initially synthesized in the rough endoplasmic reticulum as precursor polypeptides of high molecular mass. Via specific (mannose-6-phosphate) receptors, most of these precursors are transported to the lysosomes, where they are subsequently dephosphorylated and proteolytically processed to generate lysosomally localized mature forms $(7,8)$. Generally, a small fraction $(5-20 \%)$ of the newly synthesized precursors is secreted (7). The lysosomal enzymes found in serum are in their precursor form (9). If lysosomal mature forms enter the circulation, e. g. because of cell damage or experimental infusion, they are rapidly cleared via specific receptors which recognize mannose/ $\mathrm{N}$-acetylglucosamine, and which are located mainly on macrophages and non-parenchymal liver cells $(10,11)$. Thus, the increased serum $\beta$-hexosaminidase activity in 
liver disease is probably derived from the increased synthesis or decreased elimination of precursor forms from the serum.

The aim of the present study was to obtain more information about $\beta$-hexosaminidase activities in liver tissue and serum and their interrelations in liver disease. We therefore performed a prospective study on fresh liver biopsy specimens from patients with different liver diseases, and compared the immunohistochemical and biochemical findings. Furthermore, in some patients, we analysed $\beta$-hexosaminidase activity in both the liver biopsy and in the serum, sampled at the same time.

\section{Materials and Methods}

Material

A total of 91 consecutive liver biopsies from the Department of Internal Medicine, University Hospital in Lund, Sweden, were included (tab. 1). The biopsies were obtained from 88 patients, 48 males and 40 females, age range was 18 to 84 years. The different diagnostic groups and the number of liver biopsies in each group are shown in table 1 . Six patients with sclerosing cholangitis were in the early stage without cholestasis. The groups of other inflammatory diseases included 2 cases of chronic persistent hepatitis and 3 cases of granulomatous hepatitis.

In the diagnostic groups of broad disease processes (cirrhosis, steatosis and cholestasis) some specimens from the other diagnostic groups were included; the cirrhotic group included 2 specimens with alcoholic hepatitis, 4 with chronic active hepatitis and 4 with primary biliary cirrhosis; in the group of steatosis 5 specimens were from patients with alcoholic hepatitis; in the group with cholestasis 3 specimens were from patients with alcoholic hepatitis and 2 specimens were from patients with cholestatic acute hepatitis. The diagnoses were based on clinical and biopsy findings. Common histological criteria were used for diagnosis (12).

Liver biopsy was performed with the Menghini technique using a $1.6 \mathrm{~mm}$ needle (13). Part $(2-3 \mathrm{~mm})$ of the innermost of the $2-5$ $\mathrm{cm}$ long liver specimen was immediately frozen for biochemistry. The rest was fixed in $0.1 \mathrm{~mol} / \mathrm{l}$ phosphate-buffered $4 \%$ formaldehyde, $\mathrm{pH} 7.0$, embedded in paraffin, serially sectioned and stained with haematoxylin-erythrosin, MacManus after diastase, van Gieson, Fouchet, reticulin according to Gordon Sweet and Perl's iron stain.

\section{Biochemical analysis}

Blood samples were taken from 50 patients at the same time as the liver biopsies. The biochemical determination of $\beta$-hexosaminidase in serum and liver tissue has been described $(3,14)$. The fraction of the isoenzyme $\beta$-hexosaminidase $B$ was determined using enzyme immunoassay methods as earlier described (14). Serum samples from 50 apparently healthy individuals aged $18-81$ years ( 30 males and 20 females) were used as a reference group.

\section{Immunohistochemical methods}

For immunohistochemistry, sections from each biopsy were prepared on slides precoated with human albumin. $\beta$-Hexosaminidase was localized by the avidin-biotin-peroxidase $(15,16)$ and alkaline phosphatase anti-alkaline phosphatase (17) methods. Monoclonal, antibody $2 \mathrm{E} 3$ reacting with $\beta$-hexosaminidase $\mathrm{A}$ and $\mathrm{B}$ and monoclonal antibody 7E4 specific for $\beta$-hexosaminidase $A$ were ap- propriately diluted $(6,18,19)$. Nègative and positive controls were prepared as described $(6,19)$.

Chemicals were purchased from Dakopatts, Copenhagen, Denmark, and from Sigma, St. Louis, MI, U. S. A.

\section{Statistical calculation il}

The results are expressed as mean $\pm \mathrm{SD}$. Statistical significance $(p<0.05)$ was tested with the Mann-Whitney rank sum test. Spearman's rank correlation test was used to determine correlation coefficients.

\section{Results}

Liver specimens histologically judged as normal $(n=11)$ showed no $\beta$-hexosaminidase immunoreactivity. Ten of these biopsies were performed because the liver enzymes were increased in the serum (high alkaline phosphatase, $\gamma$-glutamyltransferase and/or alanine aminotransferase). One biopsy was performed because of recurrent pancreatitis and suspected alcoholic liver disease.

Among the 80 diseased liver specimens, 46 showed a positive immunohistochemical $\beta$-hexosaminidase reaction. Granular $\beta$-hexosaminidase activity was found in the pericanalicular region of hepatocytes, but not in swollen and necrotic hepatocytes, which showed a more diffuse cytoplasmic reaction (fig. 1a). A reaction was also seen in macrophages in inflammatory infiltrates (fig. 1b), and occasionally in the bile duct epithelium and in some cells lining the sinusoids. The reaction was similar but generally weaker with 7E4 than with 2E3 antibody. Liver biopsies with negative $\beta$-hexosaminidase reaction in liver parenchymal cells always showed negative reactions in inflammatory cells.

Liver $\beta$-hexosaminidase activity was increased, although not significantly, in several groups of patients (tab. 1). The highest activity was observed in patients with cholestasis. Large inter-individual variations of liver $\beta$-hexosaminidase activity were noted within the same diagnostic group (see range, tab. 1), which is why the mean increase did not attain statistical significance. The isoenzyme pattern of $\beta$-hexosaminidase was similar in all the different groups. $\beta$-Hexosaminidase $B$ constituted àbout $35-40 \%$ of the total activity.

Livers with negative immunohistochemistry had biochemical $\beta$-hexosaminidase values of $37.3 \pm 12.5 \mathrm{U} / \mathrm{g}$ protein (mean $\pm S D, n=45$ ), whereas livers with positive immunohistochemistry had values of $53.1 \pm 26.8$ $\mathrm{U} / \mathrm{g}$ protein (mean $\pm \mathrm{SD}, \mathrm{n}=46, \mathrm{p}<0.05$ ).

Thirteen liver biopsy specimens exhibiting cholestasis were from patients with acute hepatitis, alcoholic hepatitis or extrahepatic cholestasis. The immunohistochemical reaction was given by liver cells and by Kupffer cells 


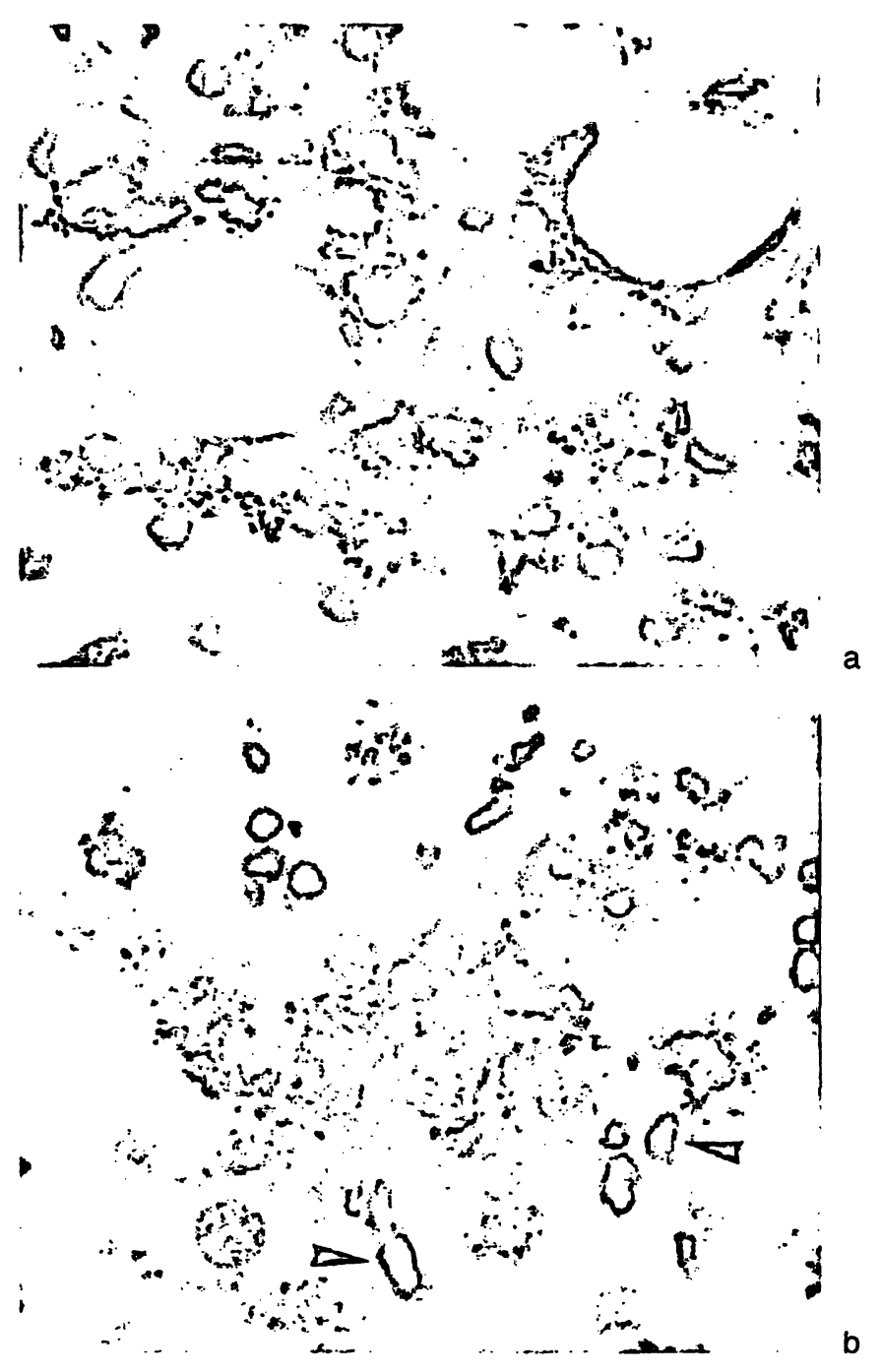

Fig. $1 \beta$-Hexosaminidase reaction

a) in steatosis. $\times 500$.

b) in primary biliary cirrhosis. $\times 500$.

The avidin-biotin-peroxidase method and $2 \mathrm{E} 3$ antibody were used in both preparations. A pericanalicular lysosomal granular reaction in hepatocytes is noted in both figures. In figure $1 \mathrm{~b}$, positive Kupffer cells can also be seen (arrows).

next to bile pigment in acinar zone 3 (around the central veins). Although the number of patients was small and cholestasis was not the only histological abnormality, retention of bile in liver tissue seemed to be associated with an increased reaction for stainable $\beta$-hexosaminidase in hepatocytes, as well as an increase of biochemical $\beta$-hexósaminidase activity in liver tissue. In five patients the cholestasis was caused by alcohol abuse. All these patients showed a positive immunohistochemical reaction and significantly $(p<0.05)$ raised liver $\beta$-hexosaminidase activity $(101.9 \pm 40.8)$, compared with the other eight patients with cholestasis $(46.5 \pm 14.7)$.

Blood samples were drawn from 50 patients at the same time as the liver biopsies (3-7 patients from each diagnostic group shown in tab. 1). The biochemical liver activity of $\beta$-hexosaminidase in these patients was 45.8 $\pm 24.3 \mathrm{U} / \mathrm{g}$ protein. They had significantly increased $\beta$ - hexosaminidase activity in serum $(25.2 \pm 11.8 \mathrm{U} / \mathrm{l}$; $\mathrm{n}=50)$, compared with normal individuals (14.0 \pm 4.2 $\mathrm{U} / \mathrm{l} ; \mathrm{n}=50)(\mathrm{p}<0.01)$. No significant correlation between $\beta$-hexosaminidase activity in liver (U/g protein) and serum (U/1 serum) in the patients with liver disease $(\mathrm{n}=50)$ was found (Spearman's rank correlation coefficient $r_{s}=0.22$ ).

\section{Discussion}

The immunohistochemical findings substantiate our earlier findings both in experimental (3) and human studies (6) showing that hepatocytes and macrophages, including Kupffer cells are the $\beta$-hexosaminidase positive elements.

The study indicates that there is a correlation between the amount of biochemical $\beta$-hexosaminidase activity and the stainable $\beta$-hexosaminidase in liver tissue. Disagreement in some cases might be due to to the different assay techniques (bio- and histochemical) or to sampling error when dividing small pieces of tissue. Liver $\beta$-hexosaminidase activity was high, particularly in patients with cholestasis, as found in earlier studies $(2,6)$. There was a large inter-individual variation within the groups and no group exhibited a significant increase compared with patients with normal findings in their liver biopsies. We also determined the proportions of $\beta$-hexosaminidase isoenzymes ( $\beta$-hexosaminidase $A$ and $B, 1 . c .(14)$ ) in the liver biopsies. $\beta$-Hexosaminidase $B$ made up $35-$ $40 \%$ of total activity, which is similar to the proportion found in sera from controls and also in sera from patients with liver disease and only moderately raised total serum $\beta$-hexosaminidase activity (14). There was no difference between the groups of patients.

When the endophagocytotic process is intense, there is an increase of lysosomes (1). Similarly, in this study as in our earlier reports $(3,6)$, the autophagocytotic process in degenerating cells is combined with an increase of $\beta$ hexosaminidase-positive granules, probably lysosomes. Confer \& Stenger (20) and Kanashima et al. (21) also found that degenerating hepatocytes initially respond by increasing the number of their lysosomes. The degenerative process by itself might therefore lead to increased lysosomal enzyme activity. Other causes for increased $\beta$-hexosaminidase activity in liver tissue might be disturbed bile flow or activated macrophages as discussed earlier (6).

We found significantly increased serum $\beta$-hexosaminidase activity in patients with liver disease in agreement with earlier findings $(2,14)$, and a non-significant increase of liver $\beta$-hexosaminidase activity. There was no correlation between serum and liver $\beta$-hexosaminid- 
Tab. 1 The level of $\beta$-hexosaminidase in liver tissue and the number of immunohistochemically positive to the total number of liver biopsies.

\begin{tabular}{|c|c|c|c|c|}
\hline \multirow[t]{2}{*}{ Diagnosis } & \multicolumn{3}{|c|}{ Liver $\beta$-hexosaminidase } & \multirow{2}{*}{$\begin{array}{l}\text { Immunohisto- } \\
\text { chemistry }\end{array}$} \\
\hline & $\begin{array}{l}\text { Total } \beta \text { - } \\
\text { hexosaminidase } \\
\text { range } \\
\text { (U/g protein) }\end{array}$ & $\begin{array}{l}\text { Total } \beta \text { - } \\
\text { hexosaminidase } \\
\text { mean } \pm \mathrm{SD} \\
(\mathrm{U} / \mathrm{g} \text { protein) }\end{array}$ & $\begin{array}{l}\text { Fraction of } \beta=\text {, } \\
\text { hexosaminidase B } \\
\text { mean } \pm \text { SD } \\
(\%)\end{array}$ & \\
\hline Normal & $(17.3-76.8)$ & $37.4 \pm 15.4$ & $38.0 \pm 6.6$ & $0 / 11$ \\
\hline Sclerosing cholangitis & $(20.0-46.1)$ & $31.2 \pm 11.5$ & $35.7 \pm 10.9$ & $0 / 6$ \\
\hline Primary biliary cirrhosis & $(26.2-59.3)$ & $40.9 \pm 10.2$ & $36.5 \pm 6.0$ & $9 / 17$ \\
\hline Chronic active hepatitis & $(33.0-82.1)$ & $41.9 \pm 17.7$ & $39.2 \pm 6.6$ & $5 / 11$ \\
\hline Acute hepatitis & $(34.9-81.0)$ & $53.9 \pm 18.7$ & $36.5 \pm 4.5$ & $7 / 8$ \\
\hline Alcoholic hepatitis & $(24.5-174.0)$ & $53.8 \pm 47.8$ & $39.2 \pm 6.2$ & $6 / 9$ \\
\hline Other inflammatory diseases & $(34.3-49.3)$ & $39.5 \pm 6.1$ & $37.2 \pm 5.2$ & $2 / 5$ \\
\hline Cirrhosis & $(23.3-92.4)$ & $47.5 \pm 19.9$ & $38.2 \pm 5.4$ & $10 / 13$ \\
\hline Steatosis & $(20.1-174.0)$ & $59.9 \pm 40.1$ & $39.6 \pm 7.9$ & $8 / 13$ \\
\hline Cholestasis & $(23.4-174.0)$ & $68.2 \pm 38.1$ & $41.2 \pm 5.8$ & $10 / 13$ \\
\hline
\end{tabular}

ase activity. One explanation for the lack of correlation might be that diseased liver cells (hepatocytes and activated macrophages/Kupffer cells) have an increased production of precursor forms of lysosomal enzymes $(7,8)$ and a preferential release of these forms into the circulation.

Increased liver lysosomal enzyme activity has been found biochemically in liver biopsies in human hepatitis, cholestasis and cirrhosis by several workers (22-25), whereas others have reported normal total enzyme values $(22,26-28)$. All these studies have, however, included rather small numbers of liver biopsies. Our results, showing the large interindividual variation of liver $\beta$-hexosaminidase within the different diagnostic groups, may explain the conflicting results of other reports.

\section{References}

1. de Duve, C. (1983) Lysosomes revisited. Eur. J. Biochem. 137, 391-397.

2. Hultberg, B. \& Isaksson, A. (1983) Isoenzyme pattern of serum $\beta$-hexosaminidase in liver disease, alcohol intoxication and pregnancy. Enzyme 30, 166-171.

3. Hultberg, B., Hägerstrand, I., Isaksson, A., Joelsson, B., Melen, K. \& Elsafi, M. (1988) Source of increased serum $\beta$ hexosaminidase in rat liver cirrhosis. Enzyme 40, 18-24.

4. Holmberg, J. T., Bergqvist, L., Hultberg, B., Hägerstrand, I., Ihse, I. \& Rydén, S. (1986) Radiolabelled colloid uptake distribution and pulmonary content and localization of lysosomal enzymes in cholestatic rats. Scand. J. Gastroenterol. 21, 291-299.

5. Holmberg, J. T., Hultberg, B., Hägerstrand, I., Ihse, I. \& Isaksson, A. (1986) Tissue contents and localization of lysosomal enzymes in cholestatic rats. Scand. J. Gastroenterol. 21, 205-214.

6. Elsafi, M. E., Hultberg, B., Hägerstrand, I., Isaksson, A. \& Stenram, U. (1990) Immunohistochemical demonstration of $\beta$ -
Patients with cholestasis and fatty liver caused by alcohol abuse showed significantly higher liver $\beta$-hexosaminidase activity than other patients with cholestasis. We reported earlier (29) that an increase of serum activity is a sensitive marker for alcohol abuse. It is possible that the cholestatic process in the liver caused by alcohol can explain the high increase of serum $\beta$-hexosaminidase in chronic alcoholism.

In conclusion, an immunohistochemical $\beta$-hexosaminidase reaction is noted mainly in hepatocytes in liver biopsies from patients with different liver diseases. There was no correlation between $\beta$-hexosaminidase activity in liver and serum. One posšible explanation for this finding might be that diseased liver cells produce greater quantities of lysosomal enzymes and release more of these into the circulation.

hexosaminidase in cirrhotic and cholestatic human livers with a monoclonal antibody. Liver $11,350-354$.

7. Skudlarek, M. D., Novak, E. K. \& Swank, R. T. (1984) Processing of lysosomal enzymes in macrophages and kidney. In: Lysosomes in Biology and Pathology, Vol. 7 (Dingle, I. T., Dean, R. T. \& Sly, W., eds.) Amsterdam, Elsevier, pp. 17-44.

8. Creek, K. E. \& Sly, W. S. (1984) The role of phospho-mannosyl receptor in the transport of acid hydrolases to the lysosomes. In: Lysosomes in Biology and Pathology, Vol. 7 (Dingle, I. T., Dean, R. T. \& Sly, W. S., eds.) Amsterdam, Elsevier, pp. 63-82.

9. Zühlsdorf, M., Imort; M., Hasilik, A. \& von Figura, K. (1983) Molecular forms of $\beta$-hexosaminidase and cathepsin $D$ in serum and urine of healthy subjects and patients with elevated activity of lysosomal enzymes. Biochem. J. 213, 733-740.

10. Steer, C., Kusiak, J. W., Brady, R. O. \& Jones, E. A. (1979) Selective uptake of human $\beta$-hexosaminidase $A$ by specific glycoprotein recognition system on sinusoidal cells. Proc. Nat. Acad. Sci. USA 76, 2775-27\%8. 
11. Ullrich, K., Gieselman, V., Mersmann, G. \& von Figura, K. (1979) Endocytosis of lysosomal enzymes by non-parenchymal rat liver cells. Biochem. J. 182, 329-335.

12. Schcuer, P. S. (1988) Liver Biopsy Interpretation. BalliereTindall, 4th edition, London, W. B. Saunders.

13. Menghini, G. (1958) One-second needle biopsy of the liver. Gastrocntcrol. 35, 190-195.

14. Isaksson, A. \& Hultberg, B. (1989) Immunoassay of $\beta$-hexosaminidase isoenzymes in serum in patients with raised total activities. Clin. Chim. Acta 183, 155-162.

15. Hsu, S. M., Raine, L. \& Fanger, H. (1981) A comparative study of the peroxidase antiperoxidase method and an avidinbiotin complex method for studying polypcptide hormones with radioimmunoassay antibodies. Am. J. Clin. Pathol. 75, 734-738.

16. Wood, G. S. \& Warnke, R. (1981) Suppression of endogenous avidin binding activity in tissues and its relevance to biotinavidin detection system. J. Histochem. Cytochem. 29, 11961204.

17. Cordel, J. L., Falini, B., Erber, W. N., Ghosh, A. K., Abdulaziz, Z., MacDonald, F., Pulford, K. A. F., Stein, H. \& Mason, D. (1984) Immunoenzymatic labelling of monoclonal antibodies using immune complexes of alkaline phosphatase and monoclonal anti-alkaline phosphatase (APAAP). J. Histochem. Cytochem. 32, 219-229.

18. Isaksson, A., Hultberg, B., Masson, P., Löw, K., Sundgren, E. \& Lundblad, A. (1989) Enzyme immunoassay of $\beta$-hexosaminidase isoenzymes using monoclonal antibodies. Scand. J. Clin. Lab. Invest. 49, 597-603.

19. Elsafi, M. E., Isaksson, A., Hägerstrand, I., Hultberg, B. \& Stenram, U. (1990) Immunohistochemical demonstration of $\beta$ hexosaminidase in human placental and renal tissue with mono-clonal antibodies. Virchows Archiv 59, 313-319.

20. Confer, D. B. \& Stenger, R. J. (1964) The evolution of lysosomes in hypoxic liver parenchyma as seen with the electron microscope. Am. J. Pathol. 45, 533-541.
21. Kanashima, R., Nagasue, N., Kohuo, H. \& Inokuchi, K. (1983) Changes in lysosomes of hypertrophying and atrophying liver: A comparative study of acid hydrolases contents in blood and liver in rats. Hepato-gastroenterology 30, 42-47.

22. Robinson, D. B., Diven, W. F. \& Glcw, R. H. (1982) Altered $\alpha$-mannosidase isoenzymes in the liver in hepatic cirrhosis. Enzyme 27, 99-107.

23. Schneider, M., Pott, G., Müller, K. \& Gerlach, U. (1980) Activity of isoenzyme $A$ of $\mathrm{N}$-acetyl- $\beta$-D-glucosaminidase in fibrotic liver tissue. Hepato-gastrocnterology 27, 465-467.

24. Pott, G., Eberhardt, G. \& Gerlach, U. (1979) Activity of procollagen-propyl-hydroxylase and $\mathrm{N}$-acetyl- $\beta$-glucosaminidase in liver biopsies from patients with chronic liver disease. Klin. Wochenschr. 57, 587-588.

25. Kyaw, A., Aung, T., Htut, T., Hyint, H. \& Tin, K. M. (1983) Lysosomal enzyme activities in normals and in patients with chronic liver diseases. Clin. Chim. Acta 131, 317-323.

26. Scymour, C. A. \& Peters, T. J. (1978) Changes in hepatic enzymes and organelles in alcoholic liver disease. Clin. Sci. Mol. Med. 55, 383-389.

27. Björkerud, S., Björntorp, P. \& Scherstén, T. (1967) Lysosomal enzyme activity in human liver in relation to the age of the patients and in cases with obstructive jaundice. Scand. J. Clin. Invest. 20, 224-230.

28. Pagliaro, L., Giglio, F., Moli, S. \& Catania, A. \& Citarella, P. (1964) $\beta$-Glucuronidase and acid phosphatase activities of lysosomal preparations from human liver tissue obtained by needle biopsy from subjects with acute hepatitis and cirrhosis. J. Lab. Clin. Med. 63, 977-985.

29. Hultberg, B., Isaksson, A., Berglund, M. \& Moberg, L. (1991) Serum $\beta$-hexosaminidase isoenzyme: A sensitive marker for alcohol abuse. Alcohol Clin. Exp. Res. 15, 549-552.

Dr. Björn Hultberg
Department of Clinical Chemistry
University Hospital
S-221 85 Lund
Sweden




\section{.}

